\title{
EFFECTS OF MORPHINE UPON THE ISOLATED SMALL INTESTINE OF RATS, RABBITS AND GUINEA PIGS
}

\author{
Takesi Hukuhara, Hiroyuki Fukuda And Toshiaki Neya \\ Department of Physiology, Okayama University Medical School, Okayama
}

\begin{abstract}
Recently Hukuhara, Kotani and $\mathrm{SATO}^{\text {7) }}$ found that morphine always exerted an excitatory action on the motility of dog jejunal Thiry-loop, literature concerned being reviewed there. They drew a conclusion that morphine acted as an excitant to the intestinal muscle itself, since it could raise the intestinal motility after atropine as well as hexamethonium had been administered and on the other hand it could augment the motility of the aganglionic loop. On the isolated guinea-pig small intestine, however, TRENDELENBURG ${ }^{15}$ ) concluded that the inhibition was the usual effect of morphine upon the socalled 'peristalsis'. This conclusion was supported by subsequent investigators. ${ }^{1,9,10,11,12)}$ Our doubts were then cast upon the problem whether the discrepancy existing between our results and the investigators mentioned above could, in fact, be attributable to the species difference or not. In order to solve this problem the effects of morphine upon the motility of the isolated small intestine of rats, rabbits and guinea pigs were studied. In the present experiments the action of drugs was judged by observing the rhythmic contraction waves, which were recorded by means of MAGNus' as well as TRENDELENBURG's method. That the so-called peristalsis was nothing but an enhanced rhythmic contraction wave was emphasized in the report published recently ${ }^{8}$.
\end{abstract}

\section{METHODS}

The animals used were 20 rats $(150-200 \mathrm{~g}), 30$ guinea pigs $(300-800 \mathrm{~g})$ and 2 rabbits (2500-3000 g). The abdominal cavity of the animals was opened under the local anesthetization with $1 \%$ cocaine solution. One or two duodenal, jejunal and ileal loops each 3 to $5 \mathrm{~cm}$ in length were removed from the body successively with the time interval of 40 minutes, within which an experiment was finished. In one series of experiments MAGNUS' method was used: Both ends of the loops were ligated with cotton threads to suspend in a $100 \mathrm{ml}$ bath with Tyrode solution as shown in Fig. 1,

Received for publication February 28, 1966.

福原 武, 福田博之, 袮屋俊昭. 
B. The contractions were recorded on the drum of the kymograph by means of GoHARA's ${ }^{4)}$ lever. The constituents of the solution were modified according to TAKEMA$\mathrm{SA}^{13,14)}$ as follows : $0.221 \mathrm{M}-\mathrm{NaCl}, 0.0028 \mathrm{M}-\mathrm{KCl}, 0.0015 \mathrm{M}_{-} \mathrm{CaCl}_{2}, 0.0024 \mathrm{M}-\mathrm{NaHCO}_{3}, 0.00032 \mathrm{M}$ $\mathrm{NaH}_{2} \mathrm{PO}_{4}$ and $0.010 \mathrm{M}$-Glucose. The bath consisted of a double-walled glass vessel, and the lumen of the wall was continuously perfused with water warmed to about $38^{\circ} \mathrm{C}$ to keep the temperature of the bath constant at $37^{\circ} \mathrm{C}$, into which tiny bubbles of oxygen gas was transferred through a finely perforated ceramic ball, care being taken to cover the preparations fully with the streams of bubbles.

Sometimes one of the loops was removed with its mesenteric bundle of blood vessels and nerves attached, and the nerves were set on the platinum electrodes which were connected with the rectangular pulse generator (Nippon Koden).

In other series of experiments TRENDELENBURG's method was used. As the criterion of the motility was adopted the volume change of the loop, which enabled us to measure the change of the tone of the muscle as well as the rhythm and amplitude of the intestinal movement. The change of the length of the loop was

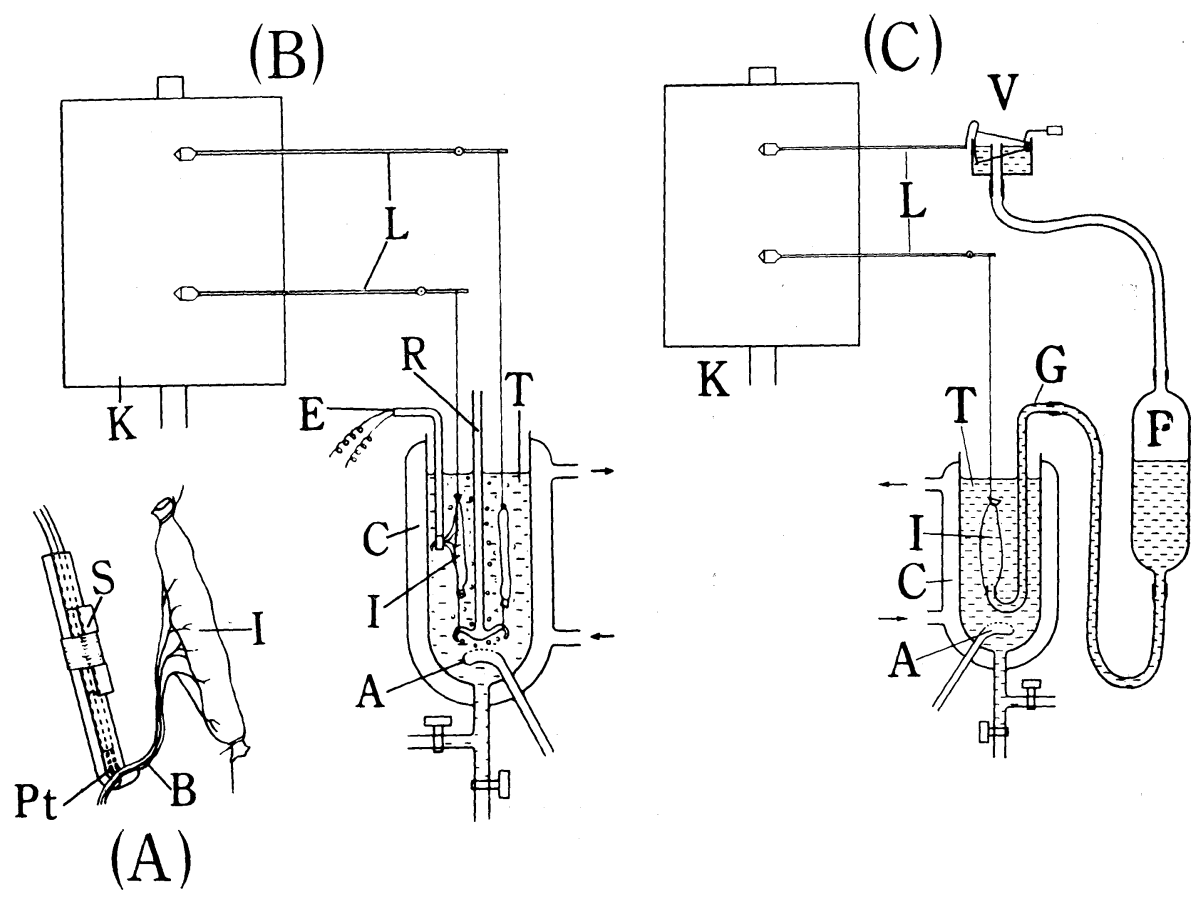

FIG. 1. Arrangements for experiments on the isolated intestinal loops. (A): The electrodes used for stimulating the mesenteric nerves. The nerves $B$ are laid on the curved surface of the holder and then set thereupon by moving the slider S. (B) : Arrangement for the experiment by MAGnus' method. (C) : Arrangement for the experiment by Trendelenburg's method. Pt; Platinum electrodes. $\mathrm{K}$; Kymograph. L; Recording lever. V; Volume recorder. P; Pressure bottle. G; Glass cannula. E; Electrodes holder. T; Tyrode bath. I; Intestinal loop. R; Glass rod. C; Chamber through which warmed water circulates, A; Finely perforated ceramic ball. 
also recorded but useful only for reference, because, in the light of our recent findings, ${ }^{8)}$ the change in the length of the preparation, particularly in the TREndelenBURG's method, was not always a true expression of the motility of the longitudinal muscle layer.

As a standard morphine solution $1 \mathrm{~g} / \mathrm{dl}$ morphine hydrochloride (TAKEDA)-Tyrode solution is prepared. From this solution is then prepared the one which contained the drug in various concentrations. One tenth to one $\mathrm{ml}$ of these solutions was added to the bath to obtain a desired concentration of the drug in it. The other drugs used were nicotine bitartrate (KATAYAMA), hexamethonium bromide $\left(\mathrm{C}_{6}\right)$ (YAMANOUCHI), atropine sulfate (MERCK) and 1,1-dimethyl-4-phenyl-piperazinium iodide (DMPP) (PARK, DAVIS), and they were dissolved in the distilled water, respectively, care being taken not to add more than one $\mathrm{ml}$ of the solution to avoid the effect of dilution of the Tyrode solution contained in the bath.

\section{RESULTS}

\section{A. Rats}

1) Experiments carried out by means of MAGNus' method. The time interval of ten and a few minutes elapsed, till the changes of both tone and rhythmic contractions became fairly stable. The smallest effective concentration of morphine may be $10^{-7} \mathrm{~g} / \mathrm{ml}$ or less. At these concentrations

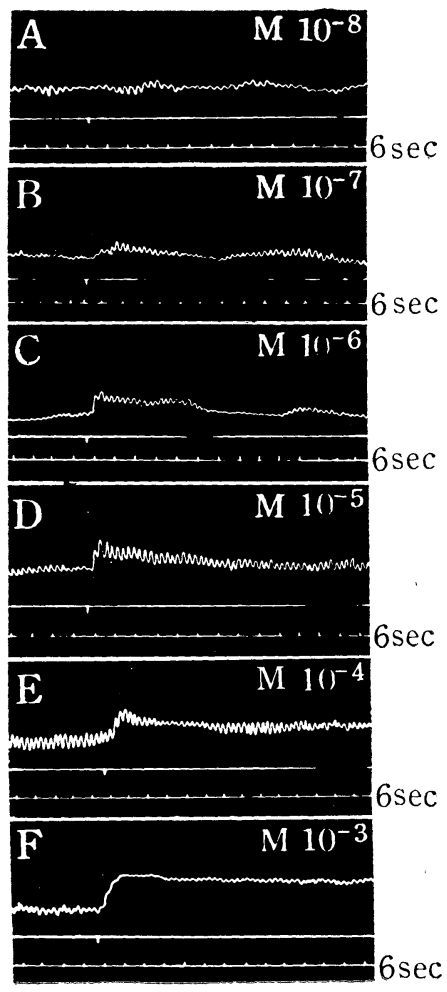

FIG. 2. The effect of morphine upon the motility of rat duodenum. MAGnus' method. Tracings from above downwards: Changes in the longitudinal direction, signal indicating the moment of addition of morphine (M), of which concentrations are shown on the right in the figures. In $\mathrm{B}$ is shown an excitatory effect at the threshold concentration of the drug. C, D, E and F show the effect at the higher concentrations which are indicated in the tracings. 
there appeared a fairly remarkable rise of tone superimposed with rhythmic contractions as shown in FIG. 2B. The higher the concentration of the drug was, the more pronounced became the excitatory effect as shown in FIG. 2C, $\mathrm{D}, \mathrm{E}$ and $\mathrm{F}$.

Fifty seconds after administering the ganglion blocking agent, nicotine $\left(5 \times 10^{-5} \mathrm{~g} / \mathrm{ml}\right)$, which transitorily produced the inhibitory effect followed by the excitatory one, morphine produced the excitatory effect in almost the same degree as that observed before the administration of nicotine (FIG. 3). Naturally, within several tens of seconds thereafter the second administration of nicotine was ineffective.
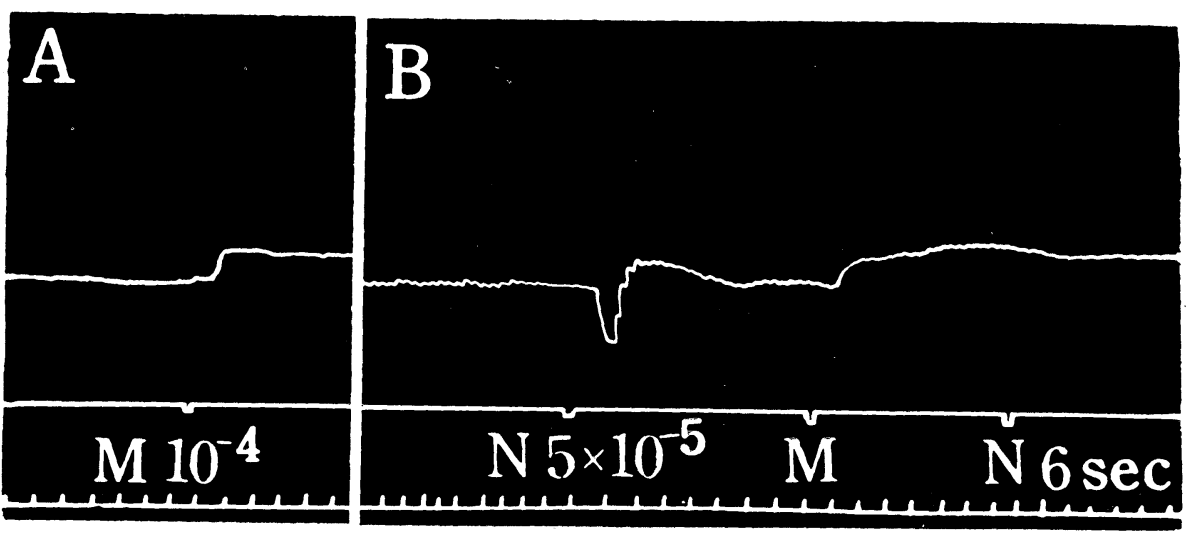

FIs. 3. The effect of morphine upon the motility of rat duodenum. MAGNus' method. In tracings, $A$ and $B$, is indicated the effect of morphine before and after the administration of nicotine, respectively. Between $A$ and $B$ the preparation is thoroughly (three or four times) washed out. This explanation applies for subsequent figures. Note that after administering nicotine $(\mathrm{N})$ morphine $(\mathrm{M})$ produces the excitatory effect in the same degree as that observed before the administration of the drug.

After administering the ganglion blocking agent, $\mathrm{C}_{6}\left(5 \times 10^{-4} \mathrm{~g} / \mathrm{ml}\right)$, at the concentration of $10^{-4} \mathrm{~g} / \mathrm{ml}$ morphine also produced the excitatory effect in the same degree as that observed before the administration of $\mathrm{C}_{6}$ (FIG. 4).

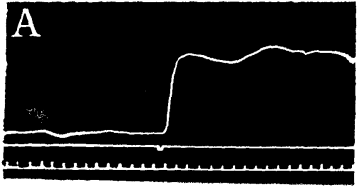

M $10^{-4}$

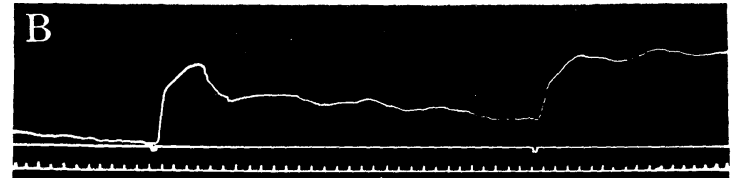

$\mathrm{C}_{6} 5 \times 10^{-4}$
M $10^{-4}$

FIG. 4. The effect of morphine upon the motility of rat duodenum. MAGNus' method. In tracings, $A$ and $B$, is indicated the effect of morphine before and after the administration of $\left(\mathrm{C}_{6}\right)$, respectively. In each case morphine $(\mathrm{M})$ always produces a remarkable excitatory effect. 
From the results described above it could be presumed that morphine exerted an excitatory action upon the axons of intramural ganglion cells and/ or the intestinal muscle itself. The evidence had been obtained that the intestinal wall contained two kinds of intramural ganglion cells, that is, the excitatory cholinergic and inhibitory adrenergic neurones. ${ }^{2,3,5,6)}$ Therefore, it could be supposed that the excitatory effect concerned might be a result of stimulation of the axon of this cholinergic neurone. The following experiments, however, revealed that such was not the case: The excitatory effect of morphine was the same as or even more remarkable than that observed before the administration of atropine $\left(10^{-4} \mathrm{~g} / \mathrm{ml}\right.$ ) (FIG. 5$)$.
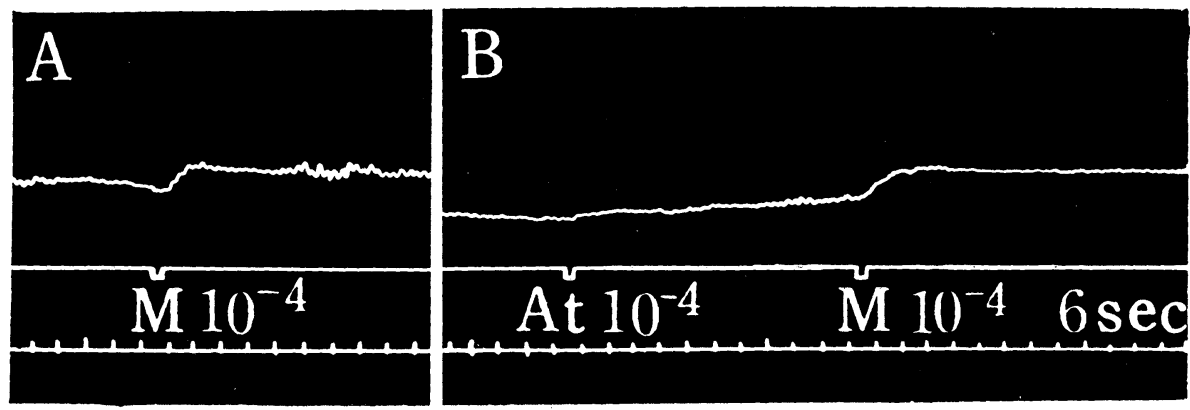

FIG. 5. Atropine does not prevent the excitatory effect of morphine on the motility of rat duodenum. MAGNus' method. In tracings, A and B, is indicated the effect of morphine upon the intestinal motility before and after the administration of atropine, respectively. $\mathrm{M}$ and $\mathrm{At}$ indicate the addition of morphine and atropine, respectively.

From the results mentioned above it could be concluded that the excitatory effect of morphine upon the intestinal motility was not due to the intramural excitatory cholinergic neurone but to the intestinal muscle itself, and that the drug did no: exert a stimulating action upon the intramural inhibitory neurone.

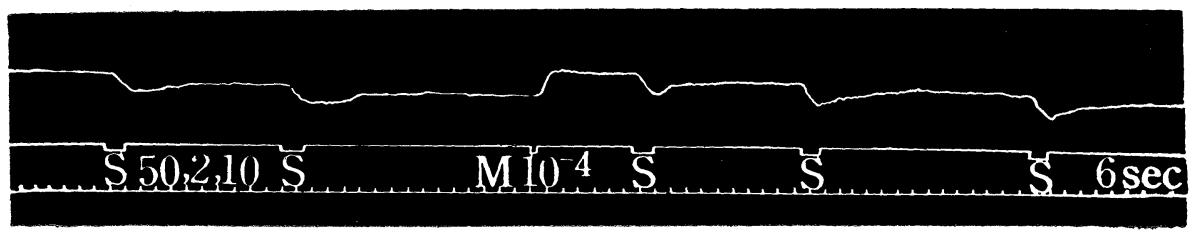

FIG. 6. Morphine has no influence upon the effect of sympathetic inhibitory nerve on the motility of rat duodenum. MAGNus' method. S indicates the moment and duration of stimulation of the mesenteric nerves of the loop. Parameters of stimulus: 10 volts, 50 shocks/sec and $2 \mathrm{msec}$ duration. Morphine is added at $M$ to the bath. 
Another series of experiments were performed to examine whether morphine had a paralyzing effect upon the sympathetic inhibitory nerve as well as intramural ganglion cells: When the mesenteric nerves were strongly stimulated, the intestinal motility was always inhibited. This effect was not altered in any way after administration of morphine as shown in FIG. 6.

On the other hand, after the administration of morphine the excitatory effect of the ganglion stimulating agent, DMPP $\left(10^{-3} \mathrm{~g} / \mathrm{ml}\right)$, was not altered, as shown in FIG. 7.

The results described above revealed that morphine had no paralyzing
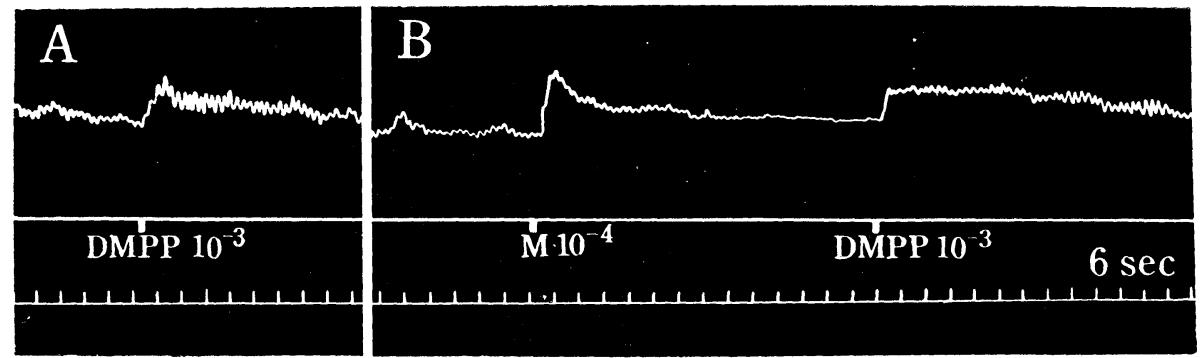

FIG. 7. Morphine does not alter the excitatory effect of DMPP. MAGnUS' method. In tracings, $A$ and $B$, is indicated the effect of DMPP upon the intestinal motility before and after the administration of morphine $(M)$, respectively.
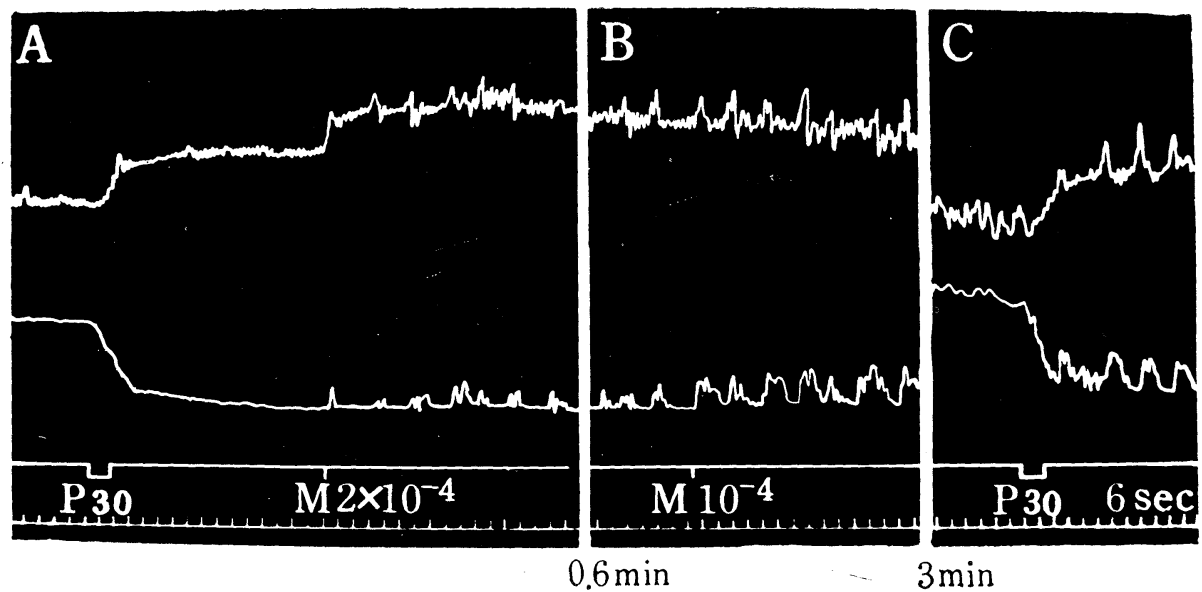

FIG. 8. Effect of morphine upon the motility of the isolated rat jejunum. TREndelenburG's method. Tracings from above downwards: Changes in the longitudinal direction, changes in the volume, signal and time in $6 \mathrm{sec} . \mathrm{P}_{30}$ indicates that at that moment the intraluminal pressure is raised as high as $30 \mathrm{mmH}_{2} \mathrm{O}$. This explanation applies for subsequent figures. Note that in $\mathrm{A}$ and $\mathrm{B}$ the excitatory effects of morphine $(\mathrm{M})$ is produced. In $\mathrm{C}$ the pressure is lowered to zero, being then again raised as high as $30 \mathrm{mmH}_{2} \mathrm{O}$. 
action on the sympathetic inhibitory nerve as well as on the synaptic area of the intramural ganglion cells.

2) Experiments carried out by means of TRENDELENBURG's method. In rats, even when the intraluminal pressure was raised as high as $30 \mathrm{mmH}_{2} \mathrm{O}$, the volume changes produced by rhythmic contraction waves were so weak that they could hardly be recorded, as shown in Fig. 8. When morphine was then added successively twice to the bath to obtain the total concentration of $3 \times 10^{-4} \mathrm{~g} / \mathrm{ml}$, rhythmic contraction waves were increased both in their tone and amplitude, although they periodically waxed and waned. And, even when the pressure was lowered to zero, rhythmic contraction waves could clearly be seen. When several tens of seconds thereafter the intraluminal pressure was then again raised as high as $30 \mathrm{mmH}_{2} \mathrm{O}$, rhythmic contractions were remarkably increased in their amplitude (FIG. $8 \mathrm{C}$ ). On 10 preparations each made from different individuals morphine always produced an excitatory effect similar to that described above, any inhibitory eff ect of the drug being not observed.

\section{B) Rabbits}

The results obtained in the experiments which were performed by means of MAgnus' as well as TRENDELENBURG's method were in essence consistent with those obtained in the experiments performed on rats. Morphine always exerted an excitatory action upon the intestinal motility, the smallest effective concentration being $10^{-6} \mathrm{~g} / \mathrm{ml}$. One example is shown in FIG. 9: When, after raising the intraluminal pressure as high as $10 \mathrm{~mm} \mathrm{H}_{2} \mathrm{O}$, morphine was successively added to the bath to obtain the concentrations such as indicated in the figure (FIG. 9), the rhythmic contraction waves were increased in their amplitude with increase of the dose of the drug added, whose total concentration was estimated to be nearly $8 \times 10^{-4} \mathrm{~g} / \mathrm{ml}$. At these concentrations of the

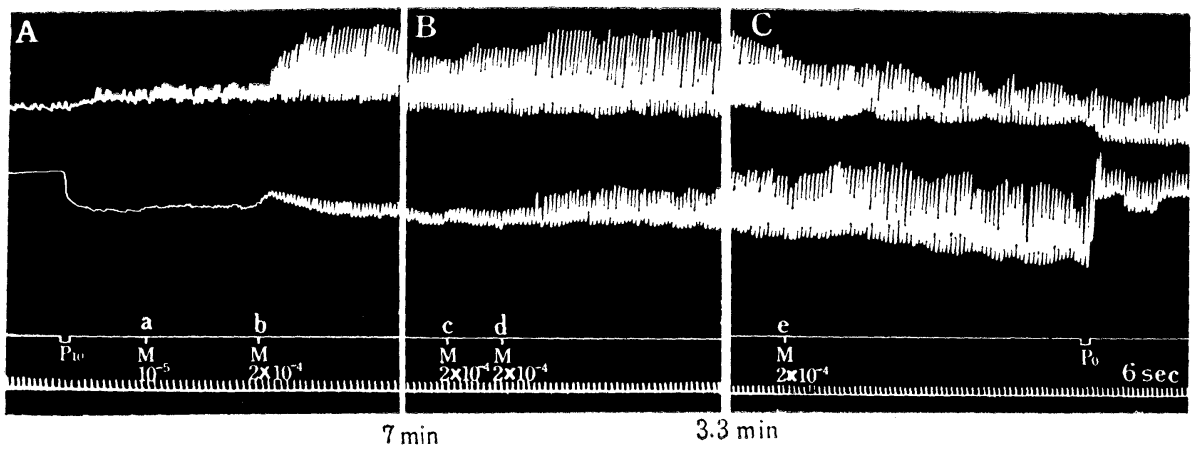

FIG. 9. Effect of morphine upon the motility of the isolated rabbit ileum. TrendelenburG's method. Tracings from above downwards: Changes in the longitudinal direction, changes in the volume, signal and time in $6 \mathrm{sec}$. The drug (M) always produces an excitatory effect. 
drug the waves were fairly powerful, even when the pressure was lowered to zero (FIG. 9, $\mathrm{P}_{0}$ ).

\section{C) Guinea pigs}

The experiments were carried out only by means of TRENDELEnBURG's method. The contractions were usually too weak to be recorded, even when the intraluminal pressure was raised as high as $25 \mathrm{mmH}_{2} \mathrm{O}$. The smallest effective concentration of morphine was $10^{-10} \mathrm{~g} / \mathrm{ml}$ or less. At these concentrations there occurred every 3 to 4 minutes a rise of the tone of a short duration (20 seconds or more), which was occasionally superimposed with weak contraction waves (FIG. 10, A).

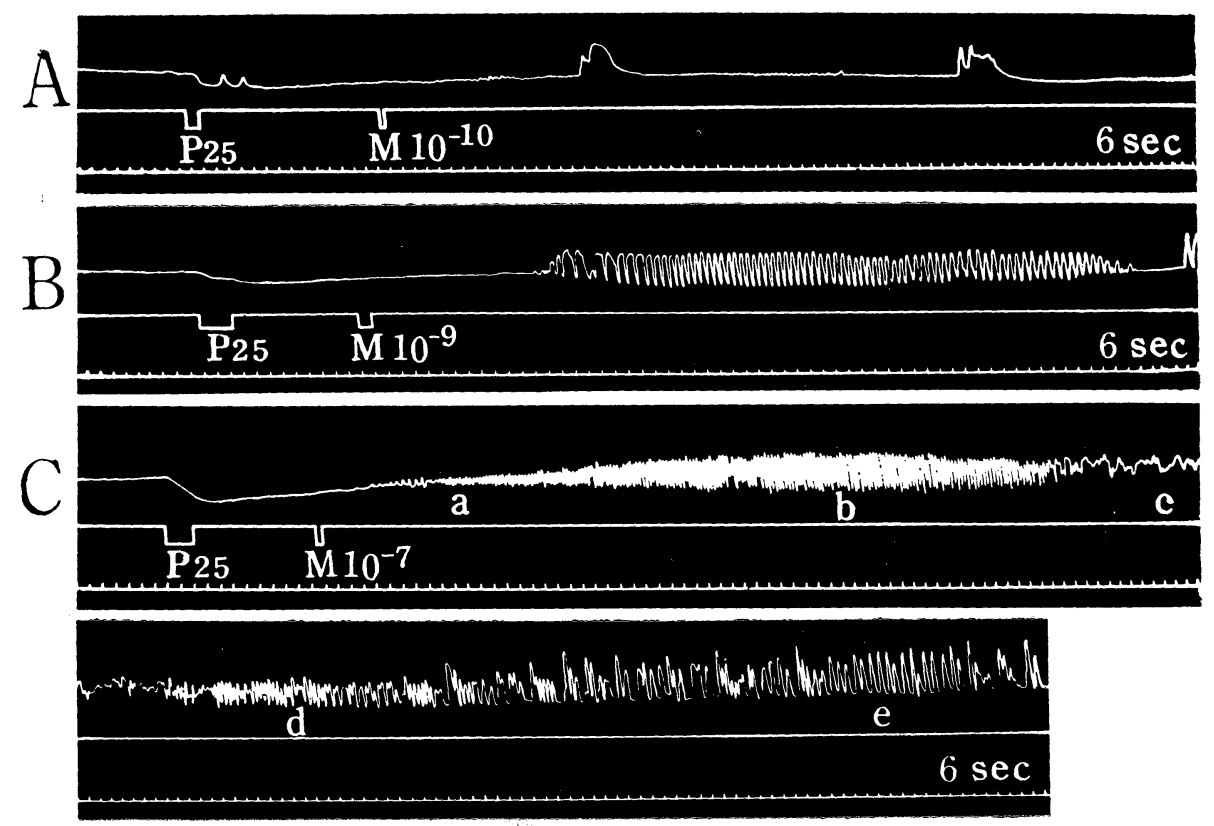

FIG. 10. Effect of morphine upon the motility of the isolated guinea-pig ileum. Trendelenburg's method. Tracings from above downwards: Changes in the volume signal and time in $6 \mathrm{sec}$. In the figures, $A, B$ and $C$, the intraluminal pressure is raised as high as $25 \mathrm{mmH}_{2} \mathrm{O}$ at $\mathrm{P}_{25}$, respectively. At $\mathrm{M}$ morphine is added to the bath, concentrations being indicated in the respective figures. It is to be noted that morphine always exerts an excitatory action upon the intestine.

At the concentration of $10^{-9} \mathrm{~g} / \mathrm{ml}$, about one minute after the administration of the drug, the preexisting, minute contraction waves were rapidly increased in their strength, until they reached a maximal strength which was maintained for 4 minutes or more. The waves were then transitorily decreased in their strength to become again powerful for a while; after that 
an augmentation and diminution of the motility alternate with a short time interval, the effect being thus gradually decreased. In the course of these changes no perceptible change of the tone could be seen, the waves propagating from oral to anal with a regular time interval of about 3 seconds (FIG. 10, B).

When the drug was administered at the concentration ranging from $10^{-8}$ to $10^{-7} \mathrm{~g} / \mathrm{ml}$, themotility was changed in the following regular sequence: In about 30 seconds after the administration of the drug the amplitude of the waves was gradually increased as shown in FIG. 10, C a to b. Then there occurred a rise of tone accompanied with the reduction of the amplitude of the waves (FIG. 10, C b to c). The tone could rise so highly that the loop took the appearance of a somewhat tortulous, elongated cord (FIG. 10, C c). After a while the loop relaxed so far as to make relatively large volume changes reappear. Now, the pacemaker region was not always confined to the oral end of the loop, but one or two pulsating rings of constriction might be produced somewhere along the loop. Since these pulsations propagated toward the adjacent regions and interfered with each other, the motility took

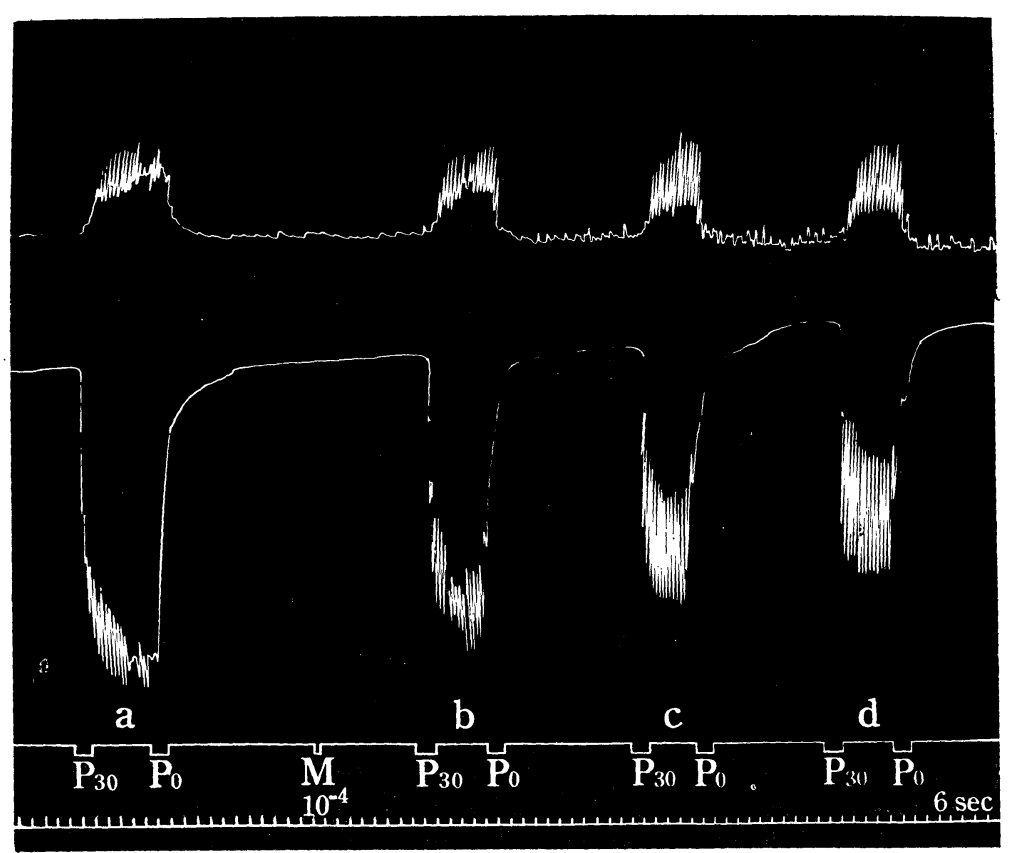

FIG. 11. Effect of morphine upon the motility of guinea-pig ileum. TRENDELENBURG'S method. The intraluminal pressure of the loop is raised successively with a time interval of about one minute as high as $30 \mathrm{mmH}_{2} \mathrm{O}$ every time for about 30 seconds. After administering morphine at $M$, with the lapse of time, the augmentation of the motility gradually becomes remarkable: The base line is elevated and the volume changes are increased in their amplitudes. 
an aspect of disorder, thus resulting in the irregularities of volume changes (FIG. 10, C d). And occasionally there appeared contraction waves with a prolonged period as shown in FIG. 10, C e.

At the concentrations ranging from $10^{-6}$ to $10^{-4} \mathrm{~g} / \mathrm{ml}$, the effect was essentially the same in its aspect as that shown in FIG. 10, C, although the degree of excitation was far more pronounced than that described above: The latency of the appearance of the effect was shortened. And the phase where the waves were regular and powerful was in a short time succeeded by that of the excessive rise of tone and irregularities of the waves.

In other series of experiments the effect of morphine on the intestinal motility was studied in the way similar to that generally adopted by previous investigators. Firstly, it was assured that when the intraluminal pressure
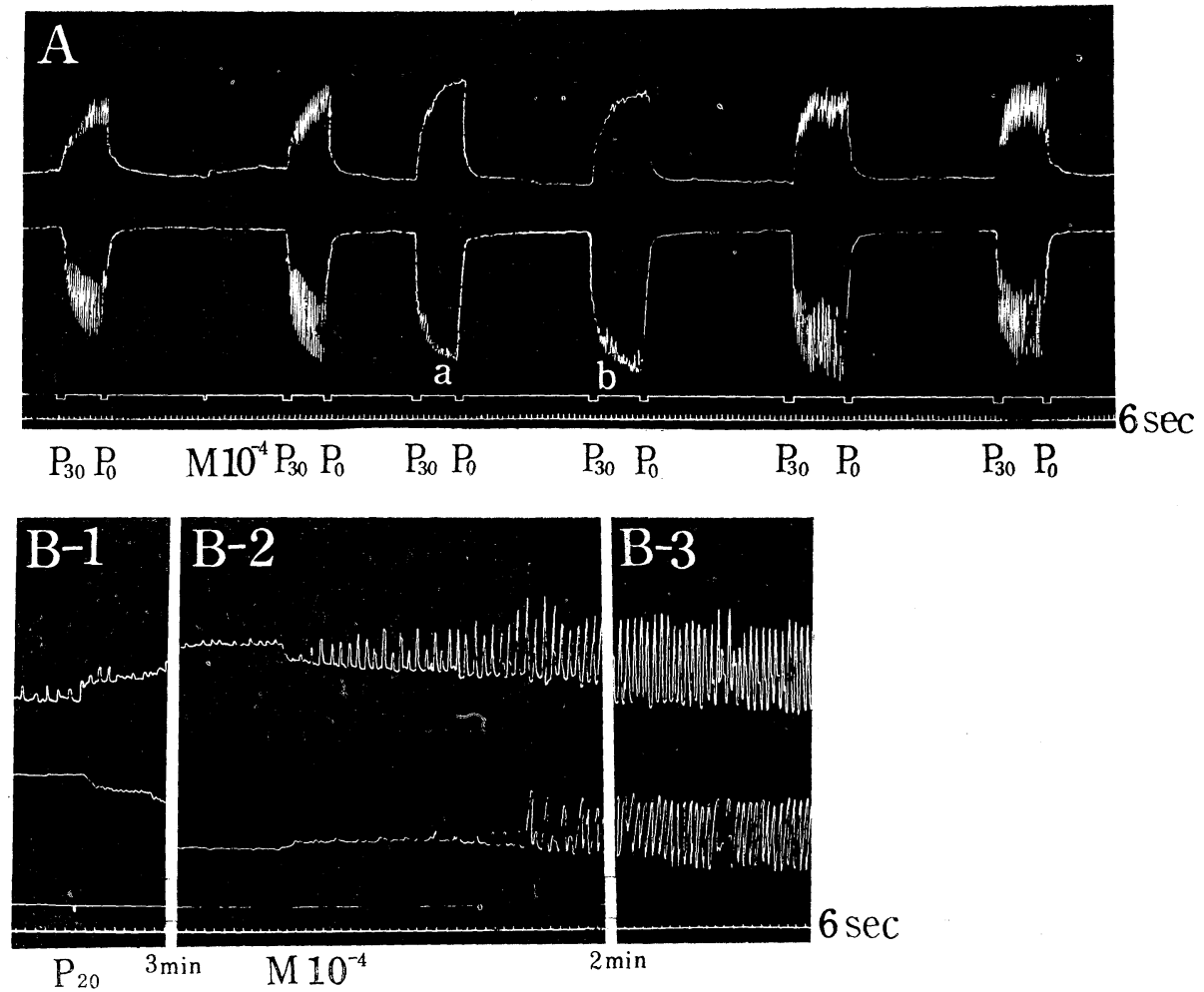

FIG. 12. Effect of morphine upon the motility of guinea-pig ileum. TRENDELENBURG's method. A : A half to 2 minutes after the administration of morphine there is a sign of inhibition of the motility, reduction or abolition of the waves being noted at $a$ and $b$. However, this inhibitory effect is soon followed by the excitatory one, as shown in subsequent tracings. B: The same loop as in A. When the intraluminal pressure of the loop is continuously maintained at $20 \mathrm{~mm}_{2} \mathrm{O}$, morphine produces nothing but the excitatory effect. 
of the loop was raised as high as $30 \mathrm{mmH}_{2} \mathrm{O}$, the contraction waves became remarkably powerful, as shown in FIG. 11, a. After morphine was administered in its effective dose $\left(10^{-4} \mathrm{~g} / \mathrm{ml}\right)$ the same trial as above mentioned revealed that in almost all cases the distensibility of the loop was decreased, while the amplitude of the waves was increased, as shown in FIG. 11, b, c and $\mathrm{d}$. These results thus revealed that morphine exerted an excitatory action on the intestinal motility. Only in two out of 50 experimental cases a sign of inhibition was recognized, as shown in FIG. 12, A which, however, persisted only a short time (0.5-2 minutes) after administration of the drug, and thereafter followed by the excitation. Curiously enough, it is, however, noted that the drug produced only the excitatory effect, when this loop was maintained continuously under the pressure as high as $20 \mathrm{mmH}_{2} \mathrm{O}$, as shown in FIG. 12, B. The mechanism underlying this inhibition is to be solved; it might be correlated with the rapid rise of the intraluminal pressure.

\section{DISCUSSIONS}

From the results obtained in the present experiments it may be concluded that morphine in most cases has an excitatory action upon the motility of the isolated small intestine of guinea pigs, rats and rabbits. The threshold concentration was found to be $10^{-10}, 10^{-7}$ and $10^{-6} \mathrm{~g} / \mathrm{ml}$ in the respective animals. At smaller concentrations the contraction waves were increased in their amplitude with or without being accompanied with a rise of the tone, while at higher concentrations there was produced a remarkable rise of the tone, which could culminate in its extreme to produce disordered contractions. Ganglion blocking agents, nicotine and hexamethonium $\left(\mathrm{C}_{6}\right)$ as well as atropine, the drug which is considered to prevent acetylcholine from acting upon the intestinal muscle, had no influence upon the excitatory action of morphine. On the other hand, morphine had no influence upon the inhibitory effect produced by the stimulation of the mesenteric nerve bundle as well as upon the excitatory effect produced by the administration of the ganglion stimulating agent, DMPP. From these results it may be concluded that morphine acts excitatorily on the intestinal muscle without acting upon the intramural nervous elements. This conclusion is largely consistent with that drawn by HukUhaRA $e t a l^{7}$ from the results obtained in the experiments on dogs in vivo.

The results mentioned above diametrically oppose those obtained on guinea pigs by TrendelenbURG ${ }^{15)}$ and the subsequent investigators, Straub and Viaud, Schaumann, ${ }^{11)}$ Kosterlitz and Robinson ${ }^{910)}$ and Beleslin, Bogdanović and RAKIĆ. Only in two out of total 50 experimental cases we, in fact, observed an inhibitory effect, which was, however, only a transitory one and followed by the phase of excitation. It is our great regret that we failed to find out 
the condition under which this inhibition would be produced: By cooling intestinal loops, changing the constituents of the Tyrode solution and decreasing the oxygen supply the usual effect of excitation could not be reversed into the inhibitory one.

On the other hand, as described above we observed that higher concentrations of morphine could produce the excessive rise of the tone superimposed with disordered waves. We believe that these changes of motility are of the same nature as those observed TRENDELENBURG ${ }^{15}$ in one third of his experimental cases, although, curiously, except for TRENDELENBURG no investigator raferred to this excitatory effect of morphine. He thought that the phenomenon was the expression of a certain particular effect of the drug to be solved. Contrary to that, we believe that the phonomenon suggests itself as one of the clear evidences that morphine excitatory action on the intestinal motility. Such disordered contractions may be produced as a result of the rise in the excitability of the muscle so excessive that the mucosal reflex ${ }^{8)}$ fails to control the direction of the waves.

\section{SUMMARY}

1. Utilizing Magnus' as well as TREndelenburg's method the action of morphine upon the motility of the isolated small intestine of rats, rabbits and guinea pigs were studied.

2. The drug almost always produced the augmentation of the intestinal motility: At smaller concentrations the contractions were increased in their amplitude with or without being accompanied with a rise of tone, while at higher concentrations there was produced a remarkable rise of tone, which could culminate in its extreme to produce disordered contractions.

3. After applying the ganglion blocking agents such as nicotine and hexamethonium as well as atropine morphine produced the excitatory effect not inferior to that observed before the application of the agents described above. On the other hand, no change was observed in the inhibitiory effect produced by the strong stimulation of the mesenteric nerves before and after the application of morphine. And furthermore, morphine did not alter the excitatory effect of the ganglion stimulating agent, DMPP.

4. From the results described above it may be concluded that morphine exerts an excitatory action solely on the intestinal muscle, without having any action on the intramural nervous elements.

\section{REFERENCES}

1) Beleslin, D. B., Bogdanović, S. E. and Rakić, M. M. (1964). The effect of mor. phine and anticholinesterases on the peristaltic reflex of the isolated guinea-pig 
ileum. Arch. int. Pharmacodyn., 149: 457-466.

2) Fukuda, H. (1966). Mechanism underlying the augmentation of the intestinal motility produced by the stimulation of the splanchnic nerve. J. Physiol. Soc. Jap. $28: 45-52$. (in Japanese)

3) Fukuda, H. (1966). On the problem whether the intestinal intramural inhibitory neurone is of an adrenergic nature or not. J. Physiol.Soc. Jap., 28: (in Japanese) (in press).

4) Gohara, A. (1917). Ueber neue Schreibhebel. Acta sholae medicinalis Kioto 2 : 399-412.

5) Hukuhara, T., Yamagami, M. And Nakayama, S. (1958). On the intestinal intrinsic reflexes. Jap. J. Physiol., 8: 9-20.

6) Hukuhara, T., Nakayama, S. And Nanba, R. (1960). Locality of receptors concerned with the extrinsic intestino-intestinal and intrinsic muscular reflex. Jap. J. Physiol., $10: 414-419$.

7) Hukuhara, T., Kotani, S. and Sato, G. (1962). The effect of morphine upon the motility of the small intestine. Jap. J. Physiol., 12: 357--364.

8) Hukuhara, T. And Fukuda, H. (1964). The motility of the isolated guinea-pig small intestine. Jap. J. Physiol., $14: 125-139$.

9) Kosterlitz, H. W. And Robinson, J. A. (1957). Inhibition of the peristaltic reflex of the isolated guinea-pig ileum. J. Physiol., 136:249-262.

10) Kosterlits, H. W. And Robinson, J. A. (1958). The inhibitory action of morphine on the contraction of the longitudinal muscle coat of the isolated guinea-pig ileum. Brit. J. Pharmacol., 13 : 296-303.

11) Schaumann, W. (1955). The paralysing action of morphine on the guinea-pig ileum. Brit. J. Pharmacol., 10: 456-461.

12) Straub, W. and Viaud, P. (1933). Studien über Darmmotilität. Arch. f. exp. Path. u. Pharmakol., $169: 1-8$.

13) Takemasa, K. (1957). On the inorganic salts in the artificial nourishing fluid for isolated intestine. J. Physiol. Soc. Jap, 19: 1217-1225. (in Japanese).

14) TAkemasa, K. (1957). On the buffer and oxygen supply in the artificial nourishing fluid for isolated intestine. J. Physiol. Sol. Jap., 19: 1226-1233. (in Japanese).

15) Trendelenburg, P. (1917). Physiolozische und pharmakologische Versuche über die Dünndarmperistaltik. Arch.f. exp. Path. u. Pharmakol., 81 : 55-129. 